\title{
RAZISKOVALNA DEJAVNOST NA ODDELKU ZA GEOGRAFIJO
}

Raziskovanje je poleg pedagoškega dela osnovno poslanstvo sodelavcev na Oddelku za geografijo Filozofske fakultete. Že v preteklosti so bila prizadevanja in rezultati na področju raziskovanja odlika geografov, $v$ zadnjih letih pa znotraj same fakultete izstopamo tako po organizaciji kot obsegu in heterogenosti raziskovalnega dela.

Podpora učiteljem je bila vseskozi organizacija raziskovanja $\mathrm{v}$ okviru programske skupine, ki je od leta 1999 do 2003 pod vodstvom M. Paka delovala v programu Geografija in regionalni razvoj. V obdobju od leta 2004 do 2008, ko je vodenje prevzel D. Plut, je programska skupina Geografija regionalnih virov in regionalni razvoj Slovenije vključevala osem učiteljev-raziskovalcev. Področje raziskovanja se je nekoliko zožilo in osredotočilo na regionalno vrednotenje naravnih in družbenih virov ter raziskave regionalnih urbanih in podeželskih struktur. Z letom 2009 in novo programsko zasnovo v okviru programske skupine Trajnostni regionalni razvoj Slovenije pa je v program vključenih kar 15 sodelavcev. Vsebina programske skupine sicer pokriva heterogenost področij, ki jih na Oddelku za geografijo razvijajo posamezni učitelji ob pomoči asistentov znotraj svojih predmetov, še zdaleč pa ta obseg ne zadošča za resnično uveljavitev znanja in raziskovalnih potencialov.

Prav z namenom povečanja obsega in področij raziskovanja je bil leta 2002 na Oddelku za geografijo ustanovljen raziskovalni center, ki je z načrtno zaposlitvijo nepedagoških sodelavcev v večjem obsegu in bolj usmerjeno pričel sodelovati na različnih razpisih ter pridobivati temeljne in aplikativne raziskovalne projekte. Sprva sta bila kot raziskovalca zaposlena D. Cigale in B. Lampič, leta 2004 pa se je raziskovalnemu centru pridružila še N. Pichler Milanović (zaposlena na Filozofski fakulteti do leta 2009). Ko je leta 2007 D. Cigale v celoti prevzel pedagoške obveznosti, je mesto raziskovalke prevzela I. Mrak. Na ta način se na Oddelku ohranja raziskovalno jedro dveh čistih raziskovalcev/raziskovalk, vzporedno pa večina zaposlenih učiteljev in asistentov dopolnilno raziskuje in sodeluje pri projektnem delu.

V zadnjih letih smo tako izpeljali številne projekte, pretežno osredotočene na okoljska vprašanja in regionalno-razvojna področja. Če so na začetku desetletja prevladovali predvsem nacionalni projekti, pa so zadnja leta vedno bolj živahne povezave s tujimi univerzami in raziskovalnimi inštitucijami. Mednarodno raziskovalno sodelovanje tako poteka v okviru večjih interdisciplinarnih evropskih in številnih bilateralnih projektov, kjer je izjemnega pomena predvsem prenos znanj in izkušenj ter soočanje različnih teoretičnih in metodoloških pristopov.

Med zaključenimi nacionalnimi projekti do leta 2008 velja posebej izpostaviti temeljni projekt o okoljskih učinkih turizma in prometa ter projekte, ki so potekali v okviru Ciljnega raziskovalnega programa in so bili interdisciplinarno zasnovani. Njihova vsebinska heterogenost odraža raziskovalno širino sodelavcev Oddelka. Proučevali smo sodobne procese na slovenskem podeželju, rezultate pa smo podkrepili z obsežno terensko raziskavo. Osredotočili smo se tudi na razvoj mest in drugih naselij v mestnih območjih (na primeru mariborske urbane regije) ter na perspektive za trajnostni razvoj varovanih območij. Vsi projekti pomenijo velik doprinos geografski stroki na metodološkem in analitičnem področju, 
hkrati pa imajo rezultati pomemben učinek na razvoj Slovenije. Pomembnejša projekta, ki trenutno potekata, sta usmerjena $v$ raziskovanje trajnostnega razvoja urbanih ekosistemov in problematiko regionalnega razvoja Spodnjega Podravja.

Mednarodni projekti so se v preteklih letih osredotočali na vsebine s področja prostorskega planiranja in razvoja ter didaktike geografije (R.A.V.E. SPACE, RePUS, CONSPACE), v projektu DERREG (7. OP) pa so predmet proučevanja dominantni globalizacijski procesi na evropskem podeželju, kar geografom predstavlja nov raziskovalni izziv. Uspeli smo se vključiti v eminentno raziskovalno sredino univerz in inštitutov iz Velike Britanije, Nemčije, Irske, Češke, Švedske, Nizozemske in Litve.

Slika 1: Terensko delo (vzorčenje...) v dolini Pod Košuto; mednarodno sodelovanje v okviru bilateralnega projekta s francoskim inštitutom CEREGE (foto: I. Mrak)

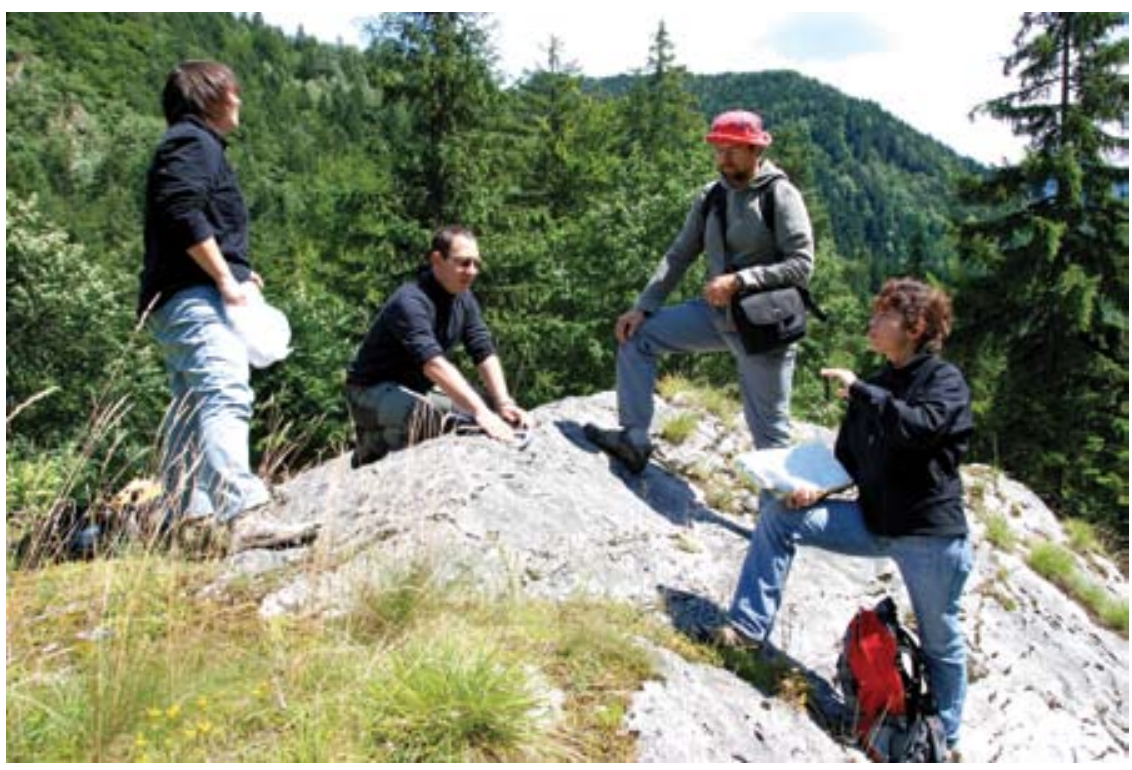

Bilateralna sodelovanja so do sedaj potekala $\mathrm{z}$ univerzami na Češkem, v Bosni in Hercegovini in v Makedoniji, v aktualnih bilateralnih projektih pa sodelujemo s Filozofsko fakulteto (Oddelek za geografijo) v Zadru, Inštitutom CEREGE iz Aix-en-Provence v Franciji (Centre Européen de Recherche et d'Enseignement des Géosciences de l'Environnement), s srbskimi geografi Univerze v Beogradu. Tovrstno sodelovanje je dobra osnova za morebitne bodoče projektne povezave, pa tudi izmenjave učiteljev in študentov.

Najpomembnejše rezultate znanstveno-raziskovalnega dela sproti objavljamo tako $\mathrm{v}$ domači kot mednarodni znanstveni literaturi, od leta 2008 tudi v novi oddelčni monografski zbirki GeograFF. Raziskovalne vsebine in metodološki pristopi zahtevajo vedno več povezovanj z drugimi strokami, zato se naše delo vedno bolj usmerja v interdisciplinarne projekte, z željo po še večji uveljavitvi tudi na mednarodni ravni. 
Raziskovalno delo dodatno bogati tudi pedagoški proces. Na eni strani gre za sprotno vključevanje aktualnih vsebin v študijske programe, istočasno pa poteka tudi vključevanje študentk in študentov $\mathrm{v}$ raziskovalno delo. $\mathrm{V}$ raziskovalnem centru lahko opravijo obvezno nepedagoško prakso in sodelujejo pri posameznih projektnih fazah. Že vrsto let je v raziskovalno delo vključena usmeritev Varstvo okolja, kjer študenti vsako leto opravijo svoj raziskovalni projekt, ki je, če je le mogoče, vezan na aktualne projekte.

Slika 2: Uvodni sestanek sodelavcev projektne skupine DERREG v Bruslju (arhiv projektne skupine DERREG)

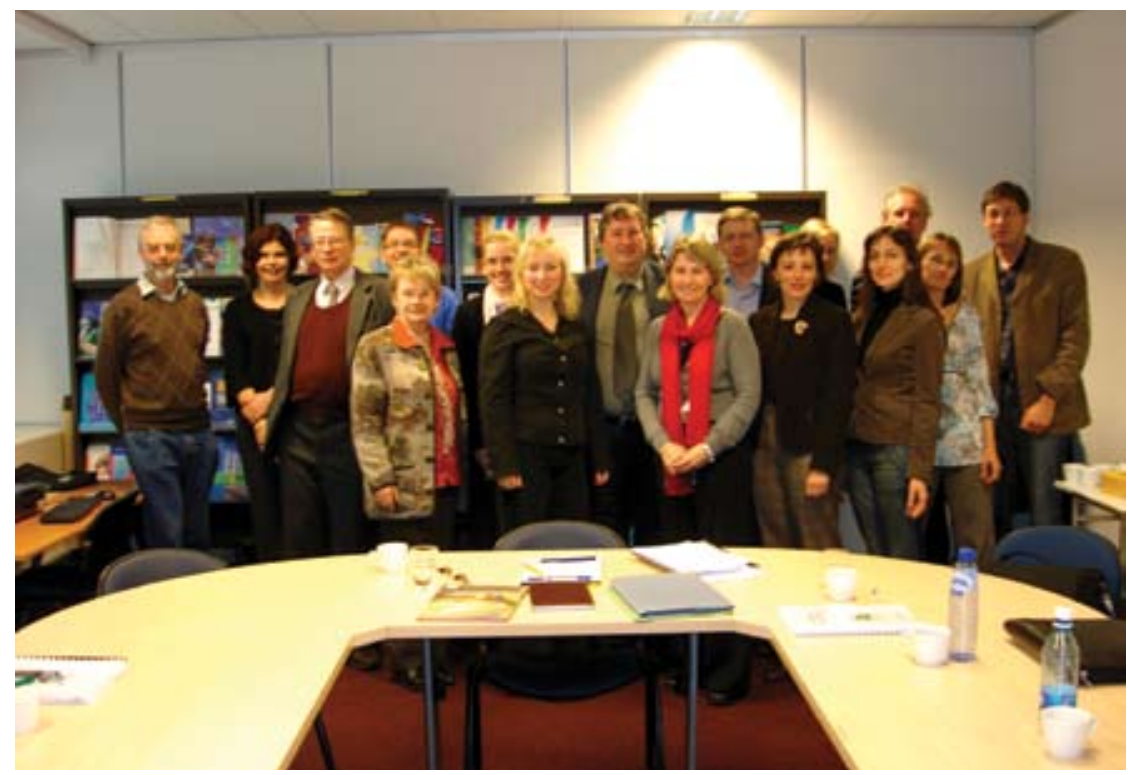

Preglednica 1: Pomembnejši projekti in raziskave, ki so v zadnjih letih potekali na Oddelku za geografijo Filozofske fakultete

\begin{tabular}{|c|c|c|}
\hline \multicolumn{3}{|l|}{ Nacionalni projekti } \\
\hline $\begin{array}{l}\text { Vrsta projekta in čas } \\
\text { izvajanja }\end{array}$ & Naslov projekta in vodja & Ključne besede \\
\hline $\begin{array}{l}\text { Aplikativni raziskovalni } \\
\text { projekt } \\
2008-2010\end{array}$ & $\begin{array}{l}\text { Značilnosti regionalnega razvoja } \\
\text { in razvojni potenciali Spodnjega } \\
\text { Podravja } \\
\text { (dr. Dejan Rebernik) }\end{array}$ & $\begin{array}{l}\text { regionalni razvoj, razvojni potenciali, } \\
\text { okoljski kapital, razvoj podeželja, vloga } \\
\text { centralnih naselij, suburbanizacija, } \\
\text { obmejna območja, Spodnje Podravje }\end{array}$ \\
\hline $\begin{array}{l}\text { Temeljni raziskovalni } \\
\text { projekt } \\
2007-2009\end{array}$ & $\begin{array}{l}\text { Trajnostni razvoj urbanih } \\
\text { ekosistemov } \\
\text { (dr. Dušan Plut) }\end{array}$ & $\begin{array}{l}\text { urbani ekosistemi, okoljski kapital, } \\
\text { trajnostni razvoj mest, Slovenija }\end{array}$ \\
\hline
\end{tabular}




\begin{tabular}{|c|c|c|}
\hline $\begin{array}{l}\text { Aplikativna raziskava } \\
\text { 2008-2009 }\end{array}$ & $\begin{array}{l}\text { Sanacija malih vodnih tokov in } \\
\text { ukrepi za zmanjševanje poplavne } \\
\text { ogroženosti Ljubljane } \\
\text { (dr. Karel Natek) }\end{array}$ & $\begin{array}{l}\text { mali vodotoki, poplavna ogroženost, } \\
\text { Mestna občina Ljubljana }\end{array}$ \\
\hline $\begin{array}{l}\text { Aplikativni raziskovalni } \\
\text { projekt (CRP) } \\
2006-2008\end{array}$ & $\begin{array}{l}\text { Trajnostni razvoj varovanih } \\
\text { območij - celostni pristop in } \\
\text { aktivna vloga države } \\
\text { (dr. Dušan Plut) }\end{array}$ & $\begin{array}{l}\text { trajnostni razvoj, zavarovana območja, } \\
\text { regionalni viri, razvojno aktiviranje, } \\
\text { upravljanje zavarovanih območij, skladen } \\
\text { regionalen razvoj, Triglavski narodni } \\
\text { park, Krajinski park Goričko, Krajinski } \\
\text { park Logarska dolina, Notranjsko-kraška } \\
\text { regija - ekoregija, Slovenija }\end{array}$ \\
\hline $\begin{array}{l}\text { Aplikativni raziskovalni } \\
\text { projekt (CRP) } \\
2006-2008\end{array}$ & $\begin{array}{l}\text { Povezovanje kriterijev in } \\
\text { ukrepov za doseganje razvoja } \\
\text { mest in drugih naselij v širšem } \\
\text { mestnem območju } \\
\text { (dr. Dejan Rebernik) }\end{array}$ & $\begin{array}{l}\text { trajnostni prostorski razvoj, mesta in } \\
\text { mestna območja, urejanje in načrtovanje } \\
\text { prostora, ukrepi, urbanistični kriteriji, } \\
\text { raba tal, zemljiška politika, stanovanjska } \\
\text { gradnja, proizvodne dejavnosti, promet, } \\
\text { trgovina, Mariborska urbana regija, } \\
\text { Slovenija }\end{array}$ \\
\hline $\begin{array}{l}\text { Raziskava } \\
2006-2007\end{array}$ & $\begin{array}{l}\text { Kategorizacija obstoječega stanja } \\
\text { poselitvenega in prometnega } \\
\text { omrežja Republike Slovenije za } \\
\text { izdelavo državnega strateškega } \\
\text { prostorskega načrta } \\
\text { (dr. Andrej Černe) }\end{array}$ & $\begin{array}{l}\text { poselitev, prometno omrežje, strateški } \\
\text { prostorski načrt, Slovenija }\end{array}$ \\
\hline $\begin{array}{l}\text { Temeljni raziskovalni } \\
\text { projekt } \\
2004-2007\end{array}$ & $\begin{array}{l}\text { Promet in turizem v luči njunih } \\
\text { okoljskih učinkov } \\
\text { (dr. Metka Špes) }\end{array}$ & $\begin{array}{l}\text { promet, turizem, okoljski učinki, } \\
\text { trajnostni razvoj, percepcija, Slovenija }\end{array}$ \\
\hline $\begin{array}{l}\text { Aplikativna raziskava } \\
2005-2007\end{array}$ & $\begin{array}{l}\text { Analiza in funkcijsko } \\
\text { vrednotenje kmetijstva z vidika } \\
\text { vplivov na naravne vire na } \\
\text { območju celotne MOL } \\
\text { (dr. Barbara Lampič) }\end{array}$ & $\begin{array}{l}\text { kmetijstvo, kmetije, naravni viri, raba } \\
\text { tal, kmetijski vnosi, vitalnost kmetij, } \\
\text { funkcije kmetijstva, trženje v kmetijstvu, } \\
\text { perspektiva kmetijstva, Mestna občina } \\
\text { Ljubljana }\end{array}$ \\
\hline $\begin{array}{l}\text { Aplikativna raziskava } \\
\text { 2005-2006 }\end{array}$ & $\begin{array}{l}\text { Okoljska analiza in presoja } \\
\text { prostorskega razvoja MOL } \mathbf{v} \\
\text { obdobju 1990-2015 } \\
\text { (dr. Dušan Plut) }\end{array}$ & $\begin{array}{l}\text { prostorski razvoj, onesnaženost okolja, } \\
\text { varstvo okolja, okoljska presoja, Mestna } \\
\text { občina Ljubljana }\end{array}$ \\
\hline $\begin{array}{l}\text { Aplikativna raziskava } \\
\text { 2005-2006 }\end{array}$ & $\begin{array}{l}\text { Prometno onesnaževanje ozračja } \\
\text { v Ljubljani znotraj avtocestnega } \\
\text { območja } \\
\text { (dr. Darko Ogrin) }\end{array}$ & $\begin{array}{l}\text { prometno onesnaževanje, meritve, } \\
\text { kvaliteta okolja, emisije, imisije, Mestna } \\
\text { občina Ljubljana }\end{array}$ \\
\hline $\begin{array}{l}\text { Aplikativni raziskovalni } \\
\text { projekt (CRP) } \\
2003-2005\end{array}$ & $\begin{array}{l}\text { Strukturni problemi in razvojni } \\
\text { izzivi slovenskega podeželja v } \\
\text { evropski razsežnosti } \\
\text { (dr. Marijan M. Klemenčič) }\end{array}$ & $\begin{array}{l}\text { podeželje, razvojne priložnosti, } \\
\text { strukturni problemi, socialno-ekonomske } \\
\text { značilnosti, obremenjevanje okolja, tipi } \\
\text { podeželskih območij, Slovenija }\end{array}$ \\
\hline
\end{tabular}




\begin{tabular}{|c|c|c|}
\hline \multicolumn{3}{|c|}{ Mednarodni projekti } \\
\hline $\begin{array}{l}\text { Vrsta projekta in čas } \\
\text { izvajanja }\end{array}$ & Naslov projekta in vodja & Ključne besede \\
\hline $\begin{array}{l}\text { Raziskovalni projekt } \\
\text { 7. OP } \\
\text { 2009-2011 }\end{array}$ & $\begin{array}{l}\text { DERREG: Developing Europe's } \\
\text { Rural Regions in the Era of } \\
\text { Globalization } \\
\text { Razvoj evropskega podeželja v } \\
\text { obdobju globalizacije } \\
\text { (dr. Barbara Lampič) }\end{array}$ & $\begin{array}{l}\text { globalizacija, podeželje, geografija, } \\
\text { obrobna območja, podjetništvo na } \\
\text { podeželju, selitve, okoljski kapital, } \\
\text { zmožnost lokalnih skupnosti za razvoj, } \\
\text { modeli razvoja podeželja, Srednja in } \\
\text { Vzhodna Evropa }\end{array}$ \\
\hline $\begin{array}{l}\text { Program INTERREG } \\
\text { III B - CADSES } \\
\text { 2005-2007 }\end{array}$ & $\begin{array}{l}\text { R.A.V.E. SPACE, Raising } \\
\text { Awareness of Values of Space } \\
\text { Through the Process of } \\
\text { Education } \\
\text { (dr. Tatjana Resnik Planinc) } \\
\end{array}$ & $\begin{array}{l}\text { vrednote prostora, prostorsko planiranje, } \\
\text { trajnostni razvoj, izobraževanje }\end{array}$ \\
\hline $\begin{array}{l}\text { Program INTERREG } \\
\text { III B } \\
2005-2007\end{array}$ & $\begin{array}{l}\text { RePUS, Strategy for a Regional } \\
\text { Polycentric Urban System in } \\
\text { Central-Eastern Europe } \\
\text { (mag. Nataša Pichler Milanović) }\end{array}$ & $\begin{array}{l}\text { urbana središča, policentrični razvoj, } \\
\text { podeželje, Evropa }\end{array}$ \\
\hline $\begin{array}{l}\text { Program INTERACT } \\
\text { 2005-2006 }\end{array}$ & $\begin{array}{l}\text { Re-Act - Regional Actors in } \\
\text { Interreg cooperation } \\
\text { (dr. Dejan Cigale) }\end{array}$ & $\begin{array}{l}\text { INTERREG III programi, integracija } \\
\text { rezultatov, regionalno planiranje, } \\
\text { upravljanje }\end{array}$ \\
\hline $\begin{array}{l}\text { Program CADSES } \\
2003-2006\end{array}$ & $\begin{array}{l}\text { CONSPACE (Common Strategy } \\
\text { Network for Spatial Development } \\
\text { and Implementation) } \\
\text { (dr. Andrej Černe) }\end{array}$ & $\begin{array}{l}\text { prostorsko planiranje in razvoj, } \\
\text { policentrične prostorske strukture, } \\
\text { regionalna središča, razmerje urbana- } \\
\text { podeželska območja }\end{array}$ \\
\hline Projekt ASO 2006 & $\begin{array}{l}\text { Sustainable Environmental } \\
\text { Research (SER) - Promoting } \\
\text { International Cooperation and } \\
\text { Mutual Assistance in Natural } \\
\text { Parks; Slovenija, Češka Republika, } \\
\text { Avstrija } \\
\text { (dr. Marko Krevs) }\end{array}$ & $\begin{array}{l}\text { zavarovana območja, območja Natura } \\
\text { 2000, klimatogeografija, hidrologija, } \\
\text { onesnaženje zraka, GIS, daljinsko } \\
\text { zaznavanje, demografske značilnosti, } \\
\text { razvoj sonaravnega turizma }\end{array}$ \\
\hline Projekt ASO 2006 & $\begin{array}{l}\text { Structural Analysis of Spatial } \\
\text { and Human Sources for } \\
\text { Interregional Cooperation in } \\
\text { Southeast Europe, Slovenia and } \\
\text { Austria } \\
\text { (dr. Jernej Zupančič) }\end{array}$ & $\begin{array}{l}\text { družbenogeografske značilnosti, politična } \\
\text { geografija, medregionalno sodelovanje, } \\
\text { JV Evropa, Slovenija, Avstrija }\end{array}$ \\
\hline
\end{tabular}

\section{Bilateralni projekti}

\begin{tabular}{|c|c|c|}
\hline Leto izvajanja & Naslov projekta in vodja & Ključne besede \\
\hline 2009-2010 & $\begin{array}{l}\text { Sodelujoča inštitucija: Inštitut } \\
\text { CEREGE, Aix-en-Provence, } \\
\text { Francija } \\
\text { Metodologija datiranja } \\
\text { reliefnih oblik in procesov ter } \\
\text { vrednotenje geodiverzitete v } \\
\text { Alpah (dr. Barbara Lampič) }\end{array}$ & $\begin{array}{l}\text { metode datiranja, geodiverziteta, } \\
\text { geomorfni procesi, zavarovana območja, } \\
\text { vrednotenje, Alpe }\end{array}$ \\
\hline
\end{tabular}




\begin{tabular}{|c|c|c|}
\hline 2009-2010 & $\begin{array}{l}\text { Sodelujoča inštitucija: Univerza v } \\
\text { Zadru, Oddelek za geografijo } \\
\text { Zavarovana območja na } \\
\text { dinarskem krasu Hrvaške in } \\
\text { Slovenije } \\
\text { (dr. Darko Ogrin) }\end{array}$ & $\begin{array}{l}\text { zavarovana območja, dinarski kras, } \\
\text { geodiverziteta, klimatogeografija, } \\
\text { Hrvaška, Slovenija }\end{array}$ \\
\hline 2008-2009 & $\begin{array}{l}\text { Sodelujoča inštitucija: Katedra za } \\
\text { prostorsko planiranje, Geografska } \\
\text { fakulteta, Univerza v Beogradu } \\
\text { Vloga strateškega planiranja, } \\
\text { primerjalnih podatkov EU } \\
\text { in GIS za prostorski razvoj } \\
\text { srednjeevropskih mest } \\
\text { (dr. Marko Krevs) }\end{array}$ & $\begin{array}{l}\text { prostorski razvoj, prostorsko planiranje, } \\
\text { srednjeevropska mesta, GIS, Ljubljana, } \\
\text { Beograd }\end{array}$ \\
\hline 2007-2008 & $\begin{array}{l}\text { Sodelujoča inštitucija: Univerza } \\
\text { v Ostravi, Oddelek za geografijo, } \\
\text { Češka } \\
\text { Ekološko kmetijstvo kot } \\
\text { razvojni potencial za podeželje } \\
\text { (dr. Barbara Lampič) }\end{array}$ & $\begin{array}{l}\text { ekološko kmetovanje, razvojni } \\
\text { potenciali, podeželje, trajnostni razvoj, } \\
\text { Slovenija, Češka }\end{array}$ \\
\hline $2005-2006$ & $\begin{array}{l}\text { Sodelujoča inštitucija: Inštitut } \\
\text { Geonika, Akademija znanosti, } \\
\text { Brno, Češka } \\
\text { Sonaravni razvoj malih mest } \\
\text { (dr. Metka Špes) }\end{array}$ & $\begin{array}{l}\text { mala mesta, sonaravni razvoj, Slovenija, } \\
\text { Češka }\end{array}$ \\
\hline $2005-2006$ & $\begin{array}{l}\text { Sodelujoča inštitucija: Univerza v } \\
\text { Tuzli, Oddelek za geografijo } \\
\text { Regionalna struktura kot } \\
\text { element selitvene dinamike } \\
\text { urbanih območij v Sloveniji in } \\
\text { BiH } \\
\text { (dr. Jernej Zupančič) }\end{array}$ & $\begin{array}{l}\text { selitvena dinamika, mednarodne } \\
\text { migracije, etnična struktura, Slovenija, } \\
\text { Bosna in Hercegovina }\end{array}$ \\
\hline $2005-2006$ & $\begin{array}{l}\text { Sodelujoča inštitucija: Univerza } \\
\text { v Pécsu, Inštitut za geografijo, } \\
\text { Madžarska } \\
\text { Migracijski procesi in } \\
\text { medetični odnosi na stičišču } \\
\text { Slovenije, Madžarske in JV } \\
\text { Evrope } \\
\text { (dr. Jernej Zupančič) }\end{array}$ & $\begin{array}{l}\text { politična geografija, migracije, } \\
\text { manjšine, Slovenija, Madžarska, JV } \\
\text { Evropa }\end{array}$ \\
\hline $2005-2006$ & $\begin{array}{l}\text { Sodelujoča inštitucija: Univerza } \\
\text { Sv. Cirila in Metoda v Skopju, } \\
\text { Inštitut za geografijo, Makedonija } \\
\text { Demografski in migracijski } \\
\text { vidiki Slovencev v Makedoniji } \\
\text { in Makedoncev v Sloveniji } \\
\text { (dr. Jernej Zupančič) }\end{array}$ & $\begin{array}{l}\text { demografske značilnosti, migracije, } \\
\text { Slovenci, Makedonija, Makedonci, } \\
\text { Slovenija }\end{array}$ \\
\hline
\end{tabular}

